\title{
The role of non-muscle myosin IIA in aggregation and invasion of human MCF-7 breast cancer cells
}

\author{
LARA DERYCKE $1, \#$, CHRISTOPHE STOVE ${ }^{2}$, ANNE-SOPHIE VERCOUTTER-EDOUART ${ }^{3}$, \\ OLIVIER DE WEVER ${ }^{1}$, LAURENT DOLLÉ ${ }^{1,5}$, NATHALIE COLPAERT ${ }^{1}$, HERMAN DEPYPERE ${ }^{4}$, \\ JEAN-CLAUDE MICHALSKI ${ }^{3}$ and MARC BRACKE*,1 \\ ${ }^{1}$ Laboratory of Experimental Cancer Research, Department of Radiation Oncology and Experimental Cancer Re- \\ search, Ghent University, Ghent, Belgium, '2Laboratory of Toxicology, Ghent University, Ghent, Belgium \\ ${ }^{3}$ Unité de Glycobiologie Structurale et Fonctionnelle, UMR CNRS/USTL n`8576, IFR 147, France \\ ${ }^{4}$ Department of Uro-Gynaecology, Ghent University, Ghent, Belgium, \\ ${ }^{5}$ Stem Cell Biology Department of Cell Biology (LIVR) Vrije Universiteit Brussel, Brussels, Belgium
}

\begin{abstract}
Human MCF-7/6 breast cancer cells differ from their MCF-7/AZ counterparts by their invasiveness in a number of assays in vitro, such as invasion of MCF-7 spheroids into embryonic chick heart fragments or type I collagen gels. Comparative proteomic analysis of these two variants revealed an identical pattern, except for a $230 \mathrm{kDa}$ protein present in the invasive MCF-7/6 variant, but hardly detectable in the non-invasive MCF-7/AZ one. This protein appeared to be the non-muscle myosin IIA heavy chain (NMIIA), also coined MYH9. Experimental inhibition of NMIIA by reducing either its expression (via stable shRNA transduction) or its function (via the specific ATPase inhibitor blebbistatin) underpinned the decisive role of NMIIA in MCF-7 cell invasion. Inhibition of NMIIA indeed blocked the invasion of MCF-7/6 cells in three-dimensional invasion substrata such as embryonic chick heart fragments and type I collagen gels. Invasiveness of MCF-7/6 cells has been related to poor formation and compaction of aggregates, due to a functionally defective E-cadherin/catenin complex. Both genetic and pharmacological inhibition of NMIIA stimulated MCF-7/6 cell aggregation. Together, these data indicate that NMIIA is a decisive protein for MCF-7 cells to invade, indicating that this molecule is a candidate for targeted anti-invasive treatment.
\end{abstract}

KEY WORDS: non-muscle myosin, MYH9, invasion, aggregation, MCF-7, breast cancer

\section{Introduction}

Tumor cell invasion and metastasis constitute the major obstacles to successful cancer treatment. Although a number of cell activities, such as extracellular proteolysis, downregulation of cell-cell adhesion and directional migration, are typically associated with cancer, their molecular mechanisms are incompletely understood. The dynamics of the actin cytoskeleton and of the cytoplasmic microtubule complex drive and steer directional migration of the tumor cells (Albiges-Rizo et al., 2009; Gimona et al., 2008). The contribution of non-muscle myosin II (NMII) and its isoforms in motor force generation and actin filament crosslinking during directional migration is only recently discovered (Conti and Adelstein 2008) and few data are available in relation to tumor invasion.

The human MCF-7 breast adenocarcinoma cell line consists of invasive and non-invasive variants (Bracke et al., 1991), and provides for this reason interesting cell couples that can help deciphering molecular mechanisms implicated in tumor invasion. So, MCF-7/6 cells differ from their MCF-7/AZ counterparts by their invasiveness in a number of assays in vitro such as invasion in embryonic tissue fragments (Bracke et al., 1991), Matrigel ${ }^{\circledR}(\mathrm{Si}-$ mon et al., 1992) and type I collagen gels (De Wever et al., 2010). Proteomic analysis of these two variants has revealed a strikingly identical pattern, except for a $230 \mathrm{kD}$ protein present in the invasive MCF-7/6 variant, but hardly detectable in the non-invasive MCF-7/AZ one. This protein appeared to be the nonmuscle myosin IIA heavy

Abbreviations used in this paper: MCF-7/6shLUC, MCF-7/6 cells mock tranduced; MCF-7/6shMYH, MCF-7/6 cells transduced with non-mucle myosin IIa gene; NMIIA, non-muscle myosin II A; NMIIB: non-muscle myosin II B.

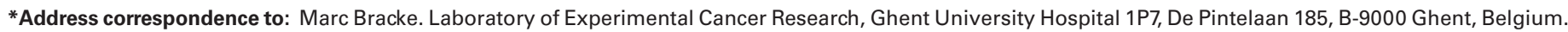
Tel: +32-9-332-3007. Fax: +32-9-332-4991. e-mail: marc1.bracke@ugent.be

\# Present address: Upper Airways Research Laboratory, Department of Otorhinolaryngology, Ghent University, Ghent, Belgium
}

Final, author-corrected PDF published online: 29 November 2011 
chain (NMIIA), also coined MYH9.

The role of NMIIA has been studied in vitro, and, although its function may differ along various cell types, interactions were identified with actin microfilaments (Eddinger and Meer 2007), microtubules (Even-Ram et al., 2007), S100A4 (Li et al., 2003), cadherin- and integrin complexes (Shewan et al., 2005; Babbin et al., 2009). Because those molecular associations can affect cell activities involved in tumor invasion, we hypothesized that NMIIA might be a critical determinant for invasion in MCF-7 cells, and, by extension, for other cancer cells. On the one hand, our strategy was based on the effect on invasion exerted by stably knocking down NMIIA using short-hairpin RNA. On the other, the effect of functional downregulation on invasion via the NMII-selective ATPase inhibitor blebbistatin (Kovacs et al., 2004) was studied as a pharmacological approach.

\section{Results}

\section{Identification of a differentially expressed protein in MCF-7 cell lines}

To dissect the molecular discriminators responsible for the difference in invasiveness between MCF-7/AZ and MCF-7/6 cells, 2D-proteomic analysis was performed on cell lysates from both cell variants and initially both profiles were founded to be very similar (Fig. 1A). However, staining of the Western blot of both cell lysates with an in-house made antibody, RAMDCK-1558 AB, initially produced against MDCK cells, revealed the presence of a differentially expressed protein at $200 \mathrm{kD}$ (Fig. 1B). To be able to identify this $200 \mathrm{kD}$ protein, a 1D SDS gel was run using cell lysates of both MCF-7 variants. Peptide mixtures resulting from the in-gel trypsin digestion of gel pieces (200 kD band) from the Coomassie-stained gel (Fig. 1C) were analyzed by MALDI-TOF mass spectrometry. Considering only protein hits that were identified with a significant score in the search engine MASCOT (Matrix Science, London), we were able to identify unambiguously the presence of non-muscle myosin IIA (NMIIA) (Mascot score: 85; 30 matched peptides with $15 \%$ sequence covered; expectation value: $\left.6.10^{-5}\right)$.

A

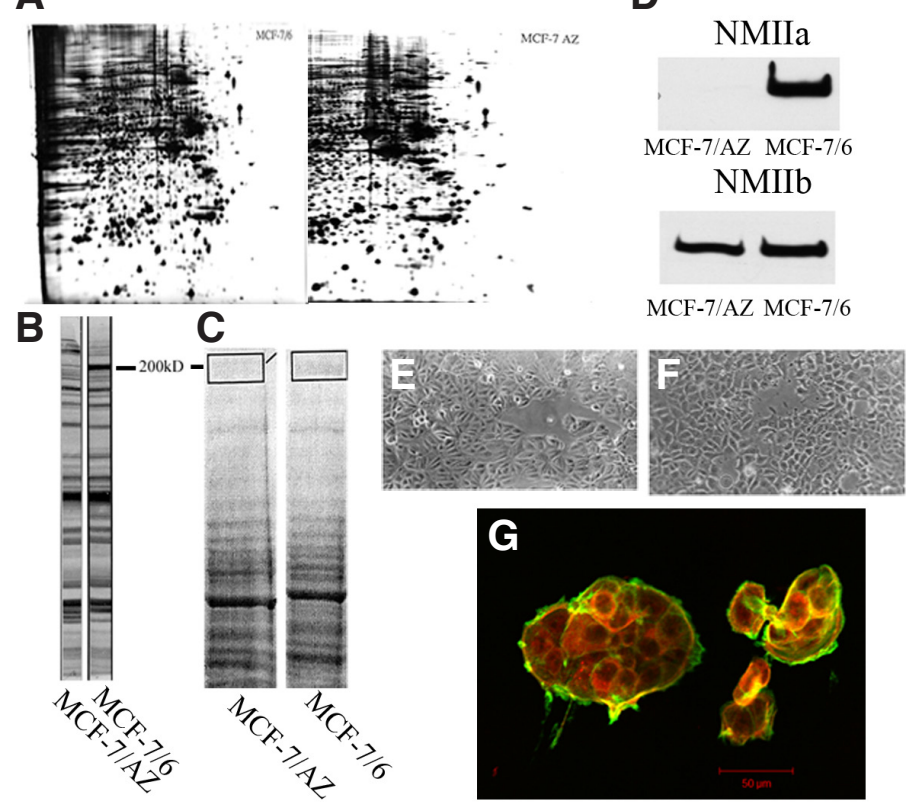

Expression of NMIIA was confirmed by Western blot analysis of lysates from both cell variants: the NMIIA heavy chain was exclusively present in MCF-7/6 cells, while the heavy chain of NMIIB was equally expressed in both cell variants (Fig. 1D). Although NMIla is known to play a role in cell-cell adhesion and motility in a number of cell lines, we could not detect morphotypical differences between the two MCF-7 variants cultured on tissue culture plastic substrata (Fig. 1EF). Immunocytochemical double stainings for NMIIA and F-actin on islands of MCF-7 cells grown on type I collagen coated substrata were analysed with laser confocal microscopy. Co-localisation of NMIIA and F-actin bundles was observed in the cortical rim of MCF-7/6 cell islands and at individual cell-cell contacts (Fig. 1G). Together, these findings show that NMIIA is a molecular discriminator for invasive MCF-7/6 cells, and that it co-localizes with F-actin bundles.

\section{Silencing of NMIIA expression promotes aggregation and in- hibits invasion of MCF-7/6 cells}

To evaluate whether the presence of NMIIA is necessary for invasion of MCF-7/6 cells, we performed knockdown of NMIIA in these cells. To this end, MCF-7/6 cells were transduced, resulting in a cell line (MCF-7/6shMYH) with stable knockdown of NMIIA, which is prerequisite, given the long period of the functional assays (up to 8 days) (Van Marck et al., 2010). As compared to native (wt) MCF-7/6 cells, the expression level of NMIIA had dropped by $70 \%$ in these cells, while transduction with a mock vector (MCF-7/6shLUC) had no effect on NMIIA expression (Fig. 2A). Silencing of NMIIA had no effect on the expression levels of NMIIB (Fig 2A).

As a first functional approach, we tested the cell aggregation capacity, because for MCF-7 variants an inverse relation has been shown earlier between their E-cadherin-dependent ability to form compact aggregates on the one hand and their invasive behaviour on the other. MCF-7/6, MCF-7/6shLUC and MCF-7/6shMYH cells were seeded on a solidified agar substratum and incubated in a humidified atmosphere at $37^{\circ} \mathrm{C}$ for $48 \mathrm{~h}$ (Fig. $2 \mathrm{~B}-\mathrm{D}$ ). Knockdown of NMIIA increased aggregation and prevented rolling of single cells along the agar meniscus towards the well centre (Debruyne et al., 2009), as observed with non-transduced or mock-transduced cells.

In a second functional approach, we tested the role of NMIIA on the invasive capacity. Therefore, spheroids were made from the different MCF-7/6 cell variants and subsequently confronted with PHFs. Non-transduced MCF-7/6 cells invaded into the heart fragments and were scored as grade 4 (Fig. 2E). Grade 4 was attributed to the confronting cultures with mock-transduced cells as well (Fig. 2F), but silencing of NMIIA resulted in interactions evaluated as grade 2 (Fig. 2G). Together, these results showed that selective NMIIA

Fig. 1. Differential expression of non-muscle myosin IIA (NMIIA) in MCF-7/6 and MCF7/AZ cells. MCF-7 variants differing in invasive capacity have identical overall profiles on two-dimensional gel-electropherograms (A), except for one spot at $200 \mathrm{kD}$, which is prominently present in the invasive MCF-7/6 cells. Using an in house antibody, RAMDCK 1588, we were able to confirm our initial finding (B). On a Coomassie blue stained SDS-PAGE of both MCF-7 variants we were able to cut out $200 \mathrm{kD}$ band. After trypsin digestion and MALDI-TOF analysis we could identify the band as nonmuscle myosin IIA (C). Western blot analysis of both cell variants confirmed that the heavy chain of NMIIA was expressed only by MCF-7/6, while the NMIIB heavy chain was expressed by both MCF-7 variants (D) Phase-contrast micrographs showed a similar morphotype for MCF-7/6 (E) and MCF-7/AZ (F) cells on tissue culture plastic. Immunocytochemical double staining of cell islands for NMIIA (red) and F-actin (green) revealed colocalization in the cortical rim of the MCF-7/6 islands (G). Scale bars, 50 um. 
A
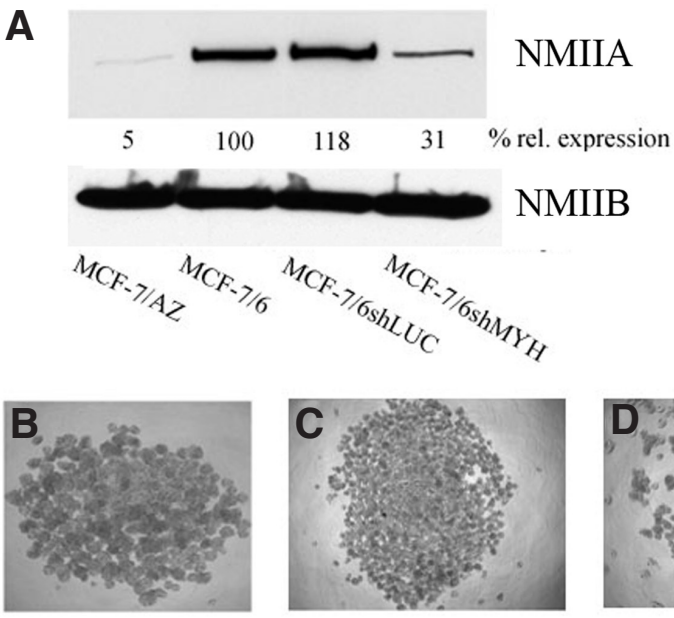

E

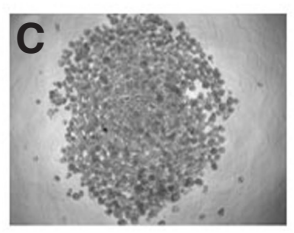

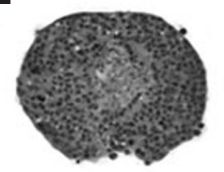

$\mathbf{F}$

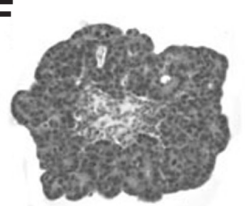

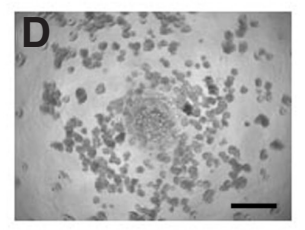

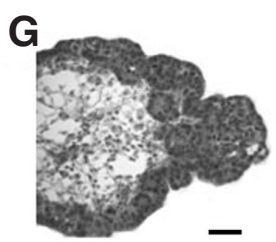

Fig. 2 (Top). Silencing of non-muscle myosin IIA (NMIIA) in MCF-7/6 cells inhibits their invasion. NMIIA was stably knockdown in MCF-7/6 cells and the Western blots of the different cell lysates, stained for the NMIIA and NMIIB heavy chain, are shown (A). The percentage of relative expression of NMIIA (to alpha-tubulin expression) is indicated for each cell type (100\% in parental MCF-7/6 cells). A 70\% knockdown of NMIIA was observed in MCF-7/6shMYC cells, as compared to non-transduced or mock-transduced (MCF-7/6shLUC) cells. Aggregation assays on agar with non-transduced (B), shLUC transduced (C) and shMYH transduced (D) MCF-7/6 cells showed that knocking down NMIIA stimulated aggregate formation and prevented rolling of single cells towards the well centre. Scale bar: $250 \mu \mathrm{m}$. From 8 um histology sections it was clear that non-transduced (E) and shLUC transduced (F) MCF-7/6 cells had invaded into precultured embryonic chick heart fragments (PHFs) afteran incubation period of 8 days. MCF-7/6 cells transduced with shMYH (G), however, were not invasive, but grew around the peripheral layers of the PHF. Photographs are representative pictures from at least 3 independent experiments. Scale bars: 50 um.
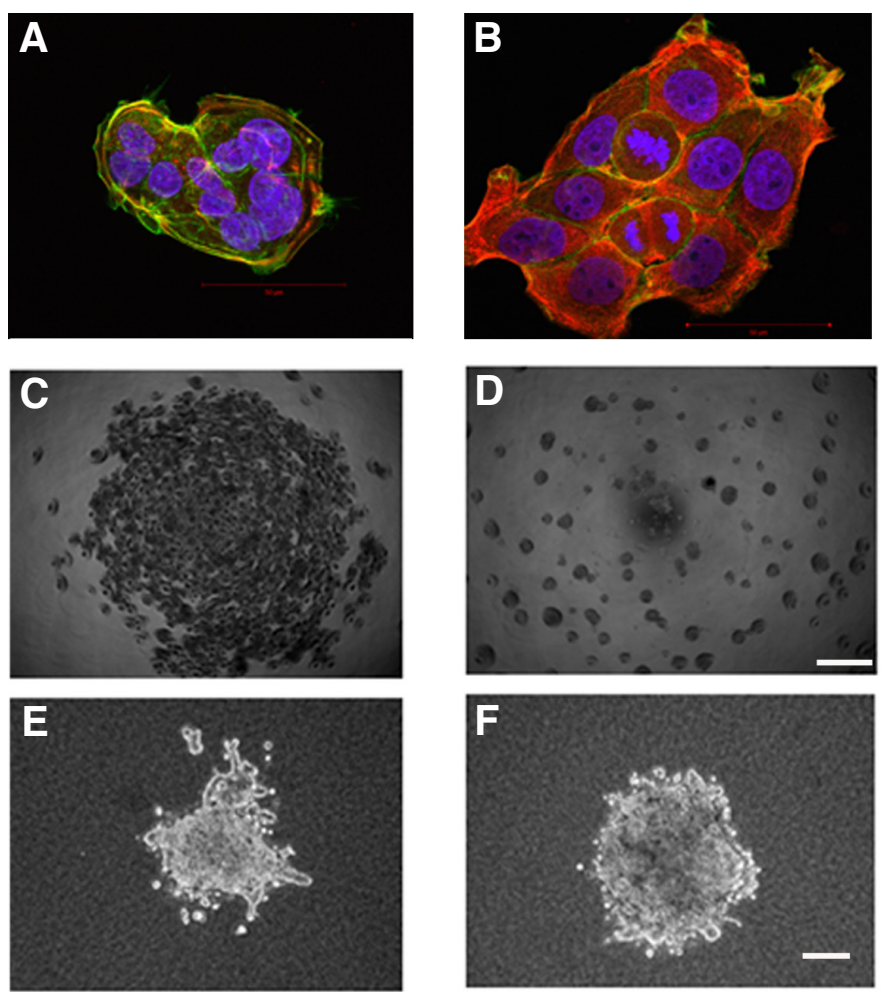

G
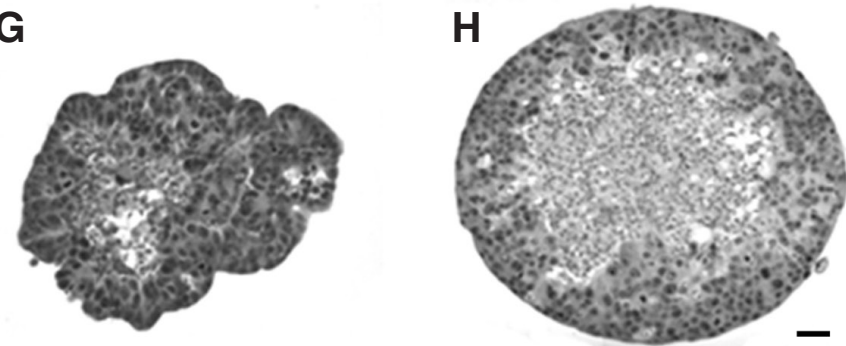

Fig. 3 (Top right). Functional inhibition of non-muscle myosin II (NMII) promotes aggregation and inhibits invasion of MCF-7/6 cells. Top row: Immunocytochemical double staining of cell islands for NMIIA (red) and F-actin (green) revealed co-localisation in the cortical rim of the MCF-7/6 islands (A) while in MCF-7/6 cells treated with blebbistatin (B) co-localisation was lost. Second row: MCF-7/6 and MCF-7/6 treated with blebbistatin were seeded on agar in a 96-well microtiter plate, and micrographs were made after $48 \mathrm{~h}$ of incubation. While aggregation of MCF-7/6 cells (C) was poor (smaller, irregular and centrally grouped aggregates), blebbistatin treatment increased aggregation in these cells (D) (compact, large aggregates). (n=6, scale bar $250 \mu \mathrm{m}$ ) Third row: Spheroids of MCF-7/6 (E) cells were inoculated in a collagen type 1 gel: after 24 h of incubation MCF-7/6 cells invaded into the collagen matrix. Blebbistatin treatment $(\mathbf{F})$ inhibited MCF-7/6 cell invasion ( $n=3)$. Bottom row: From $8 \mu m$ histology sections, it could be inferred that MCF-7/6 cells (G) had invaded into the precultured embryonic chick heart fragments (PHF) after an incubation period of 8 days. MCF-7/6 cells treated with blebbistatin $\mathbf{( H )}$, however, were not invasive and formed an organized multilayered epithelium around the PHF. Micrographs are representative for 3 independent assays. Scale bars, $50 \mu \mathrm{m}$

knockdown in MCF-7/6 cells promotes aggregation and inhibits invasion in an organotypic confrontation assay.

\section{Functional inhibition of NMII promotes aggregation and inhibits invasion of MCF-7/6 cells}

To inhibit the function of NMIIA we used the small molecule inhibitor blebbistatin, which binds to the ATPase binding pocket of the NMII heavy chain (A and B), and keeps it in an actin-detached state. MCF-7/6 cells treated with blebbistatin were analysed by immunocytochemistry. Double staining for NMIIA (red) and F-actin (green) confirmed actin detachment from NMIIA (Fig. 3 A-B) in blebbistatin-treated cells. MCF-7/6 cells were seeded on a solidified agar substratum in the presence or absence of $50 \mu \mathrm{M}$ blebbistatin, and incubated for $48 \mathrm{~h}$. Aggregates were analysed after $48 \mathrm{~h}$ (Fig. 3 C-D). MCF-7/6 cells formed smaller, irregular aggregates, grouping together in the centre of the well, while MCF-7/AZcells made larger, compact spheroid aggregates that were uniformly distributed over the well surface (data not shown, (Boterberg et al., 2000)). The presence of blebbistatin promoted aggregation of MCF-7/6 cells, and large compact spheroid aggregates were formed. 
To study the role of NMII in invasion of MCF-7/6 cells we used two in vitro invasion assays. The first one, coined spheroid invasion assay, was based on cell migration from a spheroid's periphery into a native type I collagen gel. For this, MCF-7/6 spheroids of equal size were incubated in the gel, and evaluated after $24 \mathrm{~h}$. Invasion of single cells and strands of MCF-7/6 cells into the collagen gel could be observed, which rendered the spheroids a scattered aspect (Fig. 3E). When the assay was performed in the presence of $50 \mu \mathrm{M}$ blebbistatin, invasion of the MCF-7/6 cells was blocked (Fig. 3F). In a second model we confronted MCF-7/6 spheroids with PHFs. After 8 days of incubation MCF-7/6 cells had invaded into the heart tissue and occupied more than half of the original PHF volume (grade 4). With $50 \mu \mathrm{M}$ blebbistatin in the culture medium of the confronting cultures, the invasion by MCF-7/6 cells was inhibited (grade 2) (Fig. 3 G-H).

In conclusion, inhibition of the function of NMII (A and B) in MCF-7/6 cells promotes aggregate formation and inhibits invasion into type I collagen and into normal embryonic heart tissue.

\section{Discussion}

Our study aimed to have a molecular answer for the different functional behaviour of closely related MCF-7 cells. One indication was offered by a proteomic comparison study between an invasive and a non-invasive MCF-7 variant, yielding the differential expression of NMIIA in the invasive one as a striking result. Furthermore, results from our experimental manipulations of either the expression of NMIIA (with shRNA) or of its function (with blebbistatin), underpinned the dependency of MCF-7 invasion on NMIIA activity.

No effects of NMIIA on MCF-7 cell morphology were observed when cells were kept on two-dimensional adhesive substrata like tissue culture plastic or glass. In these conditions the cells displayed a polygonal morphotype and organized into epithelioid cell islands. Here, the presence of NMIIA did not affect cell-cell contacts, and scattering was absent. A peripheral ring of bundled actin filaments was detectable in the cell islands irrespective of the presence or the functionality of NMIIA. These observations suggest that in non-migrating MCF-7 cells on two-dimensional substrata, NMIIA is neither instrumental for shape, nor for actin cytoskeleton building. Interestingly, on two-dimensional glass substrata, laminin coats have been reported to guide the cohort migration of the invasive (NMIIA+) and the non-invasive (NMIIA-) MCF-7 variants in a different direction (Coopman et al., 1991), which has also been observed for direction finding of NMIIA-dependent axonal outgrowth (Brown et al., 2009).

In three-dimensional settings a functionally active NMIIAsystem was required to observe invasion, which was defined as the progressive occupation and replacement of the surrounding tissues. This different locomotory behaviour of tumor cells in two- versus three-dimensional setups was also noticed by other investigators, and related to different signalling mechanisms. In type I collagen gels, invasion of MCF-7 cells was driven by a functionally active NMIIA system, reminiscent of the Rho-requirements reported for cell motility independent from extracellular proteolysis (Conti and Adelstein 2008; Friedl 2004). Since the invasive and non-invasive MCF-7 variants express comparable amounts of NMIIB, this isoform - in contrast to NMIIA - does not seem to be an invasion discriminator in this model. Because tumor invasion can be influenced by neighbouring host cells, which establish a micro-ecosystem for mutual molecular conversation between ligands and receptors regulating extracellular proteolysis, directional motility and cell-cell adhesion (Derycke et al., 2005), we did not restrict our study of invasion to an assay in gels without living confronting host cells. In the embryonic chick heart assay tumor cells are indeed confronted with a fragment of living host tissue. Also in this assay, invasion by the MCF-7 cells was dependent on a functionally active NMIIA system. The similarity between these observations and those obtained using type I collagen gels, indicates that the anti-invasive effect of blebbistatin is not (exclusively) related to the host tissue. In accordance with a report showing that blebbistatin prolongs suvival of cardiomyocytes in culture (Kabaeva et al., 2008), we could not observe any morphological signs of cytotoxicity of the drug on neither MCF-7 cells nor on the heart fragments after 8 days of incubation.

NMIIA has been implicated in a number of cellular activities that are directly or indirectly related to invasion. As a result of its interactions with actin microfilaments, cytoplasmic microtubules and S100A4 (metastasin), NMIIA can govern front-to-back polarity, lamellipodium formation, stress fiber and focal adhesion organisation, and contractility. In this way NMIIAcan contribute to directional migration (Conti and Adelstein 2008) and hence invasion, although some reports correlate NMIIA with inhibition of motility, and find this activity antagonistic to the one exerted by NMIIB (Sandquist et al., 2006). Moreover, our cell aggregation results revealed that poor expression, genetic knockdown or pharmacological inhibition of NMIIA increased the size of the aggregates, indicating that NMIIA inhibited adhesion between MCF-7 cells. The invasive and the noninvasive MCF-7 variant have a similar plasma membrane profile of type I cadherins: they mainly express E-, small amounts of $P$ - and no N-cadherin. Their E-cadherin/catenin complex has been characterized, but no interaction differences between the partners of the complex could be found. Upregulators of the E-cadherin function in the invasive MCF-7 variant, such as tamoxifen, insulin-like growth factor I and all-trans retinoic acid, have been described, and their effects on invasion were all inhibitory (Bracke et al., 2008). It is not clear whether or not these agents affect NMIIA, but all-trans retinoic acid downregulates NMIIA at the protein and the mRNA level (data not shown). We can only speculate on the interaction of NMIIA with the E-cadherin/catenin complex of MCF-7 cells (Ivanov et al., 2007). Shewan et al., reported on the Rho/Rho kinase signaling leading to NMII activation and E-cadherin concentration at homotypic contact sites. Furthermore, Yamada and Nelson found a role of NMII during expansion and completion of E-cadherin-mediated cell-cell adhesion sites in dog MDCK kidney cells. However, Smutny et al., described recently that NMIIA depletion markedly altered the distribution of E-cadherin, by decreasing cadherin homophilic adhesion and disruption of cadherin clustering. In our experiments, NMIIA activity also appears to inactivate E-cadherin. Here, endocytic traction on the E-cadherin/catenin complex by NMIIA (Martin et al., 2009) offers a plausible hypothesis. Pro- and anti-endocytic agents have indeed been shown to inactivate and reactivate E-cadherin's adhesion function respectively (Bracke et al., 2008). Whatever the mechanism, the interaction between the globular head region of NMIIA heavy chain and actin filaments appears to be critical, since blebbistatin, an ATPase inhibitor of this head region which keeps NMIIA in an actin-detached state (Kovacs et al., 2004), promotes MCF-7 cell-cell adhesion.

NMIIA-negative mouse embryos display defects in mesoderm 
polarization associated with a loss of cadherin concentration at cell-cell contacts (Conti et al., 2004), indicating that the molecule plays a non-redundant role in many cell types. Cell lines such as MCF-7/AZ and monkey COS-7 kidney cells, showing faint or absent expression of NMIIA, are rather exceptional cases, and in this respect it has been shown that a number of - but clearly not all - functions of different NMII isoforms can be mutually rescued (Bao et al., 2007). A recent report, showing that NMIIA is a negative predictive factor in human invasive breast cancer (Maeda et al., 2008), is in line with our observations. Moreover, Betapudi et al., described in 2006 already that NMII as important protein in the metastatic behaviour of the breast cancer cells MDA-MB-231. Furthermore, our study indicates that NMIIA is a necessary protein for MCF-7 tumor cells to invade, which opens the possibility that this molecule could be a candidate for targeted anti-invasive treatment.

\section{Materials and Methods}

\section{Cell lines}

The human breast cancer cell line variants MCF-7/AZ obtained from Per Briand (The Fibiger Institute, Copenhagen, Denmark), and MCF-7/6 from Henri Rochefort (Unité d'Endocrinologie Cellulaire et Moléculaire, Montpellier, France) were routinely maintained at $37^{\circ} \mathrm{C}$ in an atmosphere of $10 \% \mathrm{CO}_{2}$ in air, in 50\% DMEM/50\% HAMF12 (Invitrogen, Merelbeke, Belgium) with $10 \%$ heat-inactivated fetal bovine serum (Greiner Bio-one, Wemmel, Belgium), $100 \mathrm{IU} / \mathrm{mL}$ penicillin, $100 \mu \mathrm{g} / \mathrm{mL}$ streptomycin (Invitrogen) and $2.5 \mu \mathrm{g} / \mathrm{mL}$ amphotericin (Bristol-Meyers Squib, Brussels, Belgium).

\section{Antibodies and reagents}

Primary antibodies, rabbit polyclonal anti-NMIIA, rabbit polyclonal anti-NMIIB and mouse monoclonal anti-alpha-tubulin (B-5-1-2) were from Sigma (St Louis, MO, USA) and rabbit polyclonal RAMDCK-1558, against MDCK cells, was produced in our lab.

Secondary antibodies coupled to horse radish peroxidase were obtained from GE Healthcare (Diegem, Belgium). Secondary antibodies coupled to Alexa dyes for immunocytochemistry were bought from Invitrogen. Phalloidin-FITC to analyse the F-actin cytoskeleton was purchased from Sigma. Blebbistatin (Sigma) was dissolved in methanol and used at a concentration of $50 \mu \mathrm{M}$.

\section{Two-dimensional electrophoresis and protein identification}

Lysates from MCF-7/AZ and MCF-7/6 cells were loaded onto $18 \mathrm{~cm}$, pH3-10 IPG strips (Immobiline DryStrip;Amersham Biosciences, Uppsala, Sweden) after solubilization with loading and rehydration buffers for IPG strips (2M thiourea, 7M urea, 65 mM DTT, 2\% ampholytes pH 3-10, 2\% CHAPS, Genomic Solutions, Steinheim, Germany). Isoelectrofocalisation (IEF) was carried out for a total of 100,000 Vh using the Investigator 2-D Electrophoresis System (Perkin-Elmer, Coignieres, France). Following IEF, strips were equilibrated in $50 \mathrm{mM}$ Tris $\mathrm{pH} 8.8$ buffer containing $6 \mathrm{M}$ urea, $2 \%$ SDS, 30\% glycerol, and 1\% DTT for $15 \mathrm{~min}$, and then incubated for $15 \mathrm{~min}$ in the same buffer, in which DTT had been replaced with $2 \%$ iodoacetamide. The second dimension was performed on $7.5 \%-10 \%$ gradient gels (Protean II Xi system; Biorad, Marne-la-Coquette, France) and 2D-gels were silver-stained.

The spots were excised by hand and subjected to trypsin digestion overnight at $37^{\circ} \mathrm{C}$, as previously described (Gurcel et al., 2008). Recovered peptides were desalted with micro Zip-Tip C18 tips (Millipore, Molsheim, France) and spotted directly onto the MALDI-TOF MS target after elution with $60 \%$ ACN $/ 0.1 \%$ TFA containing $5 \mathrm{mg} / \mathrm{mL} \alpha$-cyano-4-hydroxycinnamic acid. MALDI-TOF analysis of trypsin digests was performed on a Voyager DE-STR PRO (Applied Biosystems, Ontario, Canada) reflector instrument in the positive ion mode and the resultant spectra were internally calibrated with trypsin autolysis fragments using DataExplorer software (Applied
Biosystems). Peptide mass fingerprinting data were evaluated using the Mascot software against the Swiss-Prot database with the following parameters: homo sapiens, one missed cleavage, and $50 \mathrm{ppm}$ mass tolerance, carbamidomethylation of cysteine, and possible oxidation of methionine.

\section{Stable knockdown}

For stable knockdown of NMIIA (MYH9), sequences were cloned into pLV-TH (Wiznerowicz and Trono 2003). Briefly, a PCR fragment consisting of part of the $\mathrm{H} 1$ promoter, the target sequence (sense), loop and target sequence (antisense) was generated by two subsequent PCR's. Afirst PCR product, with pSuper as a template, was generated using the forward primer 5'-CTGCAGGAATTCGAACGCTGACGTCATCAA-3' (with an ECoRI site indicated in italics) and as reverse primer 5'CAATCTCTTGAATTGACATCAAAGTTGATGCGGGGATCTGTGGTCTCATACAGAACTTATAA-3'. The NMIIA target sequence is indicated in bold; part of the $\mathrm{H} 1$ promotor is underlined; the loop sequence is indicated in italics. A 1000-fold dilution of this PCR product was used as a template for a second PCR, with the same forward primer and as a reverse primer 5'-CCATCGATTTCCAAAAAGCATCAACTTTGATGTCAATCTCTTGAATTGA-3', with the NMIIA target sequence indicated in bold and the Clal site in italics. PCR, cloning, production of lentiviral particles and transduction of cells was essentially as decribed before (Soubry et al., 2010). Transduced MCF-7/6 cells (MCF-7/6shMYH and mock-transduced MCF-7/6shLUC) were sorted (based on EGFP positivity) using an Epics Altra cell sorter (Beckman Coulter, Analis, Suarlée, Belgium).

\section{Slow aggregation assays}

$2 \times 10^{4}$ cells in $200 \mu \mathrm{L}$ medium were seeded on a solidified agar substratum in a 96-well microtiter plate Aggregate formation was evaluated under an inverted microscope at the indicated time points (Boterberg et al., 2001).

\section{Invasion assays}

The chick heart invasion assay was based on the confrontation in vitro between cancer cell aggregates and precultured embryonic chick heart fragments (PHFs) in organ culture (Bracke et al., 2001). PHFs were selected for a diameter of $0.4 \mathrm{~mm}$, and confronted with aggregates of MCF-7/6, MCF-7shLUC or MCF-7/6shMYH cells with a diameter of $0.2 \mathrm{~mm}$. After an overnight incubation on top of semisolid agar, the confronting pairs were cultured in suspension for 7 days. After fixation in Bouin-Hollande's solution, the cultures were embedded in paraffin, serially sectioned and stained with hematoxylin and eosin.

To make spheroids, cells were suspended as $1,5 \times 10^{5}$ cells $/ \mathrm{mL}$ in 6 $\mathrm{mL}$ DMEM+10\% FCS, and incubated in a $50-\mathrm{mL}$ Erlenmeyer flask on a gyrotory shaker at $37^{\circ} \mathrm{C}$ and $70 \mathrm{rpm}$ for 2 days. The spheroid invasion was performed as described (De Wever et al., 2010).

\section{Immunocytochemistry}

Cells were seeded on coverslips coated with collagen type I in 24-well plates, and grown until they formed cell islands. They were fixed in $3 \%$ paraformaldehyde for 20 min, blocked in PBS containing $0.1 \%$ saponin, $100 \mathrm{mM}$ glycine, and incubated with the mouse monoclonal anti-NMIIA antibody. Cells were co-stained with phalloidin-FITC to visualize the cell boundary. The rest of the procedure involved washing, incubation with donkey anti-mouse antibodies conjugated to ALEXA-555 (Invitrogen), washing again, and mounting in VectaShield (Vector Laboratories, Burlingame, CA). Cells were imaged with a Zeiss 510 META (Zeiss, Thornwood, NY). Images were acquired using a Plan Apochromat 63X/1.4 oil DIC objective. All images are 1D projections of confocal z-sections.

\section{Acknowledgements}

We thank Adeline Page from the Centre commun de mesure de spectrométrie de masse, UST (Lille, France), Marleen De Meulemeester for the help with confronting cultures, Georges De Bruyne for immunoassays and Wendy Westbroek for the help with confocal microscopy. This 
work was supported by a grant from the Research Foundation - Flanders (FWO: G.0181.07N).

\section{References}

ALBIGES-RIZO C, DESTAING O, FOURCADE B, PLANUS E, BLOCK MR (2009). Actin machinery and mechanosensitivity in invadopodia, podosomes and focal adhesions. J Cell Sci 122: 3037-3049.

BABBIN BA, KOCH S, BACHAR M, CONTI MA, PARKOS CA, ADELSTEIN RS, NUSRAT A, IVANOV AI (2009). Non-muscle myosin IIA differentially regulates intestinal epithelial cell restitution and matrix invasion. Am J Pathol 174: 436-448.

BAO J, MA X, Liu C, ADELSTEIN RS (2007). Replacement of nonmuscle myosin II-B with II-A rescues brain but not cardiac defects in mice. J Biol Chem 282: 22102-22111.

BETAPUDI V, LICATE LS, EGELHOFF TT(2006). Distinct roles of nonmuscle myosin II isoforms in the regulation of MDA-MB-231 breast cancer cell spreading and migration, Cancer Res. 66: 4725-4733.

BOTERBERG T, VENNEKENS KM, THIENPONT M (2000). Internalization of the $\mathrm{E}$-cadherin/catenin complex and scattering of human mammary carcinoma cells MCF-7/AZ after treatment with conditioned medium from human skin squamous carcinoma cells COLO 16. Cell Adhes Commun. 7: 299-310.

BOTERBERG, T., BRACKE, M.E., BRUYNEEL, E.A. and MAREEL, M.M. (2001). Cell aggregation assays. In Brooks SA, Schumacher U (ed) Methods in Molecular Medicine, vol.58: Metastasis Research Protocols, Vol 2: Cell Behavior In vitro and In Vivo. Totowa NJ: Humana Press, pp. 33-45.

BRACKE ME, VAN LAREBEKE NA, VYNCKE BM and MAREEL MM (1991). Retinoic acid modulates both invasion and plasma membrane ruffling of MCF-7 human mammary carcinoma cells in vitro. $\mathrm{Br} \mathrm{J}$ Cancer 63: 867-872.

BRACKE, M.E., BOTERBERG, T. and MAREEL, M.M. (2001). Chick heart invasion assay. In Brooks SA, Schumacher U (ed) Methods in Molecular Medicine, vol.58: Metastasis Research Protocols, Vol 2: Cell Behavior In vitro and In Vivo. Totowa NJ: Humana Press, pp. 91-102

BRACKE ME, VANHOECKE BWA, DERYCKE L, BOLCA S, POSSEMIERS S, HEYERICKA, STEVENS CV, DE KEUKELEIRED, DEPYPERE HT, VERSTRATE W, WILLIAMS CA, MCKENNAST, TOMARS, SHARMAD, PRASAD AK, DEPASS AL, PARMAR, VS (2008). Plant polyphenolics as anti-invasive cancer agents. Anti-Cancer Agents in Medicinal Chemistry 8: 171-185.

BROWN JA, WYSOLMERSKI RB, BRIDGMAN PC (2009). Dorsal root ganglion neurons react to semaphorin $3 \mathrm{~A}$ application through a biphasic response that requires multiple myosin II isoforms. Mol Biol Cell 20: 1167-1179

CONTI MA, EVEN-RAM S, LIU C, YAMADA KM, ADELSTEIN RS (2004). Defects in cell adhesion and the visceral endoderm following ablation of nonmuscle myosin heavy chain II-A in mice. J Biol Chem 279: 41263-41266.

CONTI MA, ADELSTEIN RS (2008). Nonmuscle myosin II moves in new directions. J Cell Sci 121: 11-18.

COOPMAN PJ, BRACKE ME, LISSITZKY JC, DE BRUYNE GK, VAN ROY FM, FOIDART JM and MAREEL MM (1991). Influence of basement membrane molecules on directional migration of human breast cell lines in vitro. J Cell Sci 98: 395-401.

DEBRUYNE D, MAREEL M, VANHOECKE B and BRACKE M (2009). Cell aggregation on agar as an indicator for cell-matrix adhesion: effects of opioids. In vitro Cell Dev Biol Anim 45: 473-482.

DERYCKE L, VAN MARCK V, DEPYPERE H, BRACKE M (2005). Molecular targets of growth, differentiation, tissue integrity, and ectopic cell death in cancer cells. Cancer Biother Radiopharm 20: 579-588.

DE WEVER O, HENDRIX A, DE BOECK A, WESTBROEK W, BRAEMS G, EMAMI
S, SABBAH M, GESPACH C, BRACKE M (2010). Modeling and quantification of cancer cell invasion through collagen type I matrices. Int J Dev Biol 54: 887-896.

EDDINGERTJ, MEER DP (2007). Myosin II isoforms in smooth muscle: heterogeneity and function. Am J Physiol Cell Physiol 293: C493-508.

EVEN-RAMS, DOYLEAD, CONTIMA, MATSUMOTOK, ADELSTEINRS, YAMADAK M (2007). Myosin IIA regulates cell motility and actomyosin-microtubule crosstalk. Nat Cell Biol 9: 299-309.

FRIEDL P (2004). Prespecification and plasticity: shifting mechanisms of cell migration. Curr Opin Cell Biol 16:14-23.

GIMONA M, BUCCIONE R, COURTNEIDGE SA, LINDER S (2008). Assembly and biological role of podosomes and invadopodia. Curr Opin Cell Biol 20: 235-241.

GURCEL C, VERCOUTTER-EDOUART A-S, FONBONNE C, MORTUAIRE M, SALVDOR A, MICHASKI JC, LEMOINE J (2008). Identification of new O-GICNAC modified proteins using a click-chemistry-based tagging. Anal Bioanal Chem 390: 2089-2097.

IVANOV AI, BACHAR M, BABBIN BA, ADELSTEIN RS, NUSRAT A, PARKOS CA (2007). A unique role for nonmuscle myosin heavy chain IIA in regulation of epithelial apical junctions. PloS One. 2: e658.

KABAEVA Z, ZHAO M, MICHLE DE (2008). Blebbistatin extends culture life of adult mouse cardiac myocytes and allows efficient and stable transgene expression. Am J Physiol Heart Circ Physiol 294: H1667-1674.

KOVACS M, TOTH J, HETENYI C, MALNASI-CSIZMADIA A, SELLERS JR (2004). Mechanism of blebbistatin inhibition of myosin II. J Biol Chem 279: 35557-35563.

LI ZH, SPEKTOR A, VARLAMOVA O, BRESNICK AR (2003). Mts1 regulates the assembly of nonmuscle myosin-IIA. Biochemistry 42:1 4258-4266.

MAEDA J, HIRANO T, OGIWARA A, AKIMOTO T, KAWAKAMI T, FUKUI Y, OKA T, GONG Y, GUO R, INADA H, NAWA K, KOJIKA M, SUGA Y, OHIRA T, MUKAI K, KATO H (2008). Proteomic analysis of stage I primary lung adenocarcinoma aimed at individualisation of postoperative therapy. Br J Cancer 98: 596-603.

MARTIN AC, KASCHUBE M, WIESCHAUSS EF (2009). Pulsed contractions of an actin-myosin network drive apical constriction. Nature 457: 495-499.

SANDQUIST JC, SWENSON KI, DEMALIKA, BURRIDGE K, MEANSAR (2006). Rho kinase differentially regulates phosphorylation of nonmuscle myosin II isoforms A and B during cell rounding and migration. J Biol Chem 281: 35873-35883.

SIMON N, NOEL A, FOIDART J-M (1992). Evaluation of in vitro reconstituted basement membrane assay to access the invasiveness of tumor cells. Invasion Metastasis 12: 156-167.

SHEWAN AM, MADDUGODA M, KRAEMER A, STEHBENS S, VERMA S, KOVACS EM, YAP AS (2005). Myosin 2 is a key Rho kinase target necessary for the local concentration of E-cadherin at cell-cell contacts. Mol Biol Cell 16: 4531-4542.

SMUTNY M, COX HL, LEERBERG JM, KOVACS EM, CONTI MA, FERGUSON C, HAMILTON NA, PARTON RG, ADELSTEIN RS, YAPAS (2010) Myosin II isoforms identify distinct functional modules that support integrity of the epithelial zonula adherens. Nat Cell Biol 12: 696-702.

SOUBRY A, STAES K, PARTHOENS E, NOPPEN S, STOVE C, BOGAERT P, VAN HENGEL J, VAN ROY F (2010). The transcriptional repressor Kaiso localizes at the mitotic spindle and is a constituent of the pericentriolar material. PLOS One 5: e9203.

VAN MARCK V, STOVE C, JACOBS K, VAN DEN EYDEN G, BRACKE M (2011). $\mathrm{P}$-cadherin in adhesion and invasion: Opposite roles in colon and bladder carcinoma. Int J Cancer 128: 1031-1044.

WIZNEROWICZ M, TRONO D (2003). Conditional suppression of cellular genes: lentivirus vector-mediated drug-inducible RNAinterference. J Virol77: 8957-8961.

YAMADA S, Nelson WJ (2007). Localized zones of Rho and Rac activities drive initiation and expansion of epithelial cell-cell adhesion. J Cell Biol 178: 517-527. 


\section{Further Related Reading, published previously in the Int. J. Dev. Biol.}

Epithelial-Mesenchymal Transitions in development and disease: old views and new perspectives M. Angela Nieto

Int. J. Dev. Biol. (2009) 53: 1541-1547

\section{Epithelial resealing}

Beatriz Garcia-Fernandez, Isabel Campos, Jennifer Geiger, Ana C. Santos and Antonio Jacinto Int. J. Dev. Biol. (2009) 53: 1549-1556

Collective cell migration in morphogenesis and cancer Peter Friedl, Yael Hegerfeldt and Miriam Tusch

Int. J. Dev. Biol. (2004) 48: 441-449

Cytoskeletal mechanisms responsible for invasive migration of neoplastic cells Jury M. Vasiliev

Int. J. Dev. Biol. (2004) 48: 425-439

Cadherin-mediated cell-cell adhesion and tissue segregation in relation to malignancy Ramsey A. Foty and Malcolm S. Steinberg

Int. J. Dev. Biol. (2004) 48: 397-409

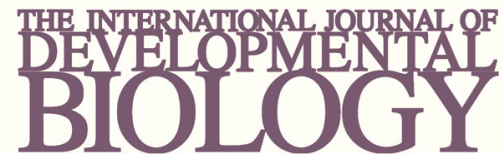

Volume 54 Nos. $6 / 7$

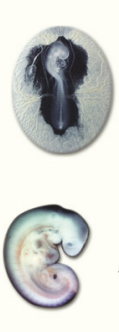

Special Issue
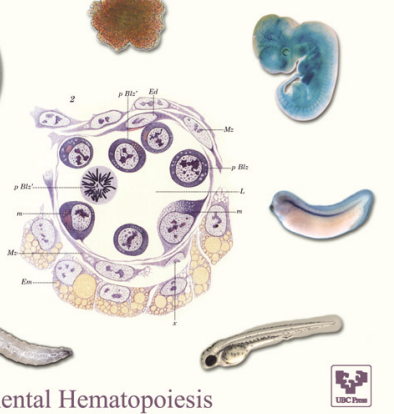

5 yr ISI Impact Factor $(2010)=2.961$

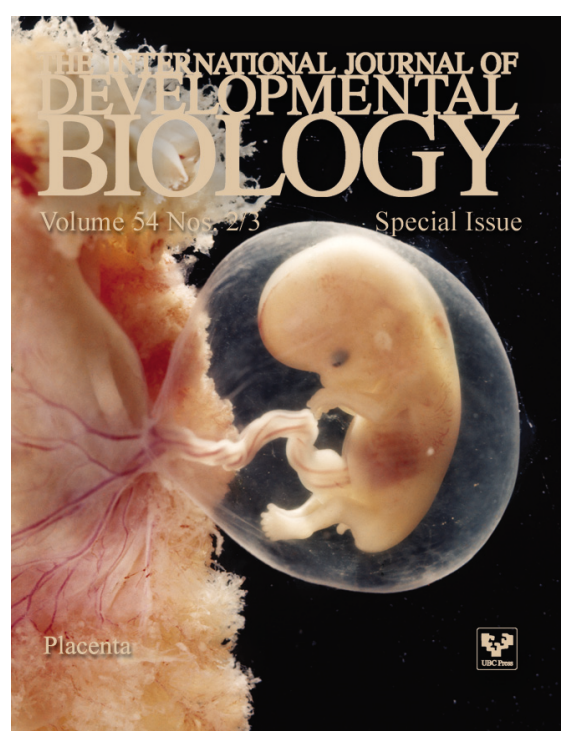

THE INTERNATIONAL JOURNAL OF DEVELOPMENTAL BOLOUY

Volume 55 Nos. $4 / 5$

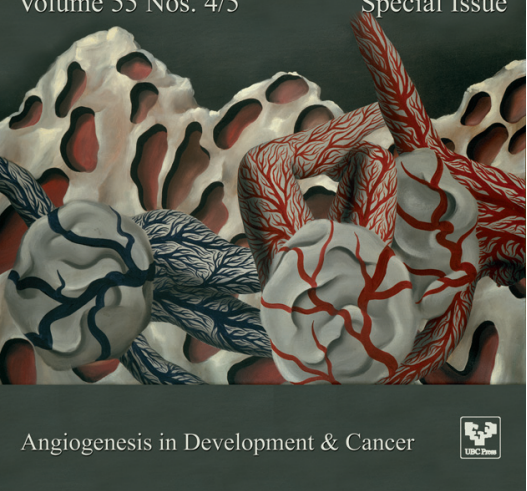

